\title{
The Significance of Emerging Technologies in Promoting Internationalization of Rural SMEs in South Africa
}

\author{
Lawrence Mpele Lekhanya \\ Durban University of Technology, South Africa \\ Email: lekhanyam@yahoo.com or Lawrencel@dut.ac.za
}

Doi:10.5901/mjss.2014.v5n20p2717

\begin{abstract}
Internationalization of rural SMEs can be able to assist in building of rural economic development in the developing countries including South Africa. Because of their characteristics, SMEs are far more flexible and responsive to frequent changes that occur in the contemporary, global environment than large enterprises. This paper intends to analyse the significance of emerging technologies in promoting internationalization of rural SMEs in South Africa. The paper also analyses the most frequent problems of rural SMEs failure to use emerging technologies as a strategic tool to promote internationalization. The primary data was collect using quantitative method. Data was collected from five rural areas of the KwaZulu-Natal (KZN) Province. The sample consisted of 374 SMEs owners/managers, selected using a quota sampling method, with respondents completing five-point Likert scale questionnaire with the assistance of an interviewer. The results reveal that the majority of respondents believe that emerging technology is a very important promotional tool that can be used by rural SMEs to access the international markets; however, the findings also indicate that rural SMEs in rural KZN are affected by lack of technology standards/networks. Further research should aim to develop training capacity building programmes that will provide entrepreneurial skills and encourage entrepreneurial technology innovation and use of new technologies among rural dwellers particularly in KZN.
\end{abstract}

Keywords: SMEs, Internationalization, Emerging technologies, Rural, Significance

\section{Introduction}

International growth has become a matter of high importance even for SMEs (Oseh, 2013). Internationalisation has become increasingly important to the competitiveness of enterprises of all sizes. In today's environment, small and medium-sized enterprises (SMEs) that start with a global strategy can move quickly to take advantage of cross-border activities, which provide opportunities not only for revenue growth but also the exchange of knowledge and the enhancement of capabilities, which strengthen the long-term competitiveness of the firm (Wilson, 2013). Tahirou, Jouali \& Arwata (2013) indicate that various factors including contingency, networking, information and external factors are critical for these organizations internationalization. They also reveal that government support, manager's motivational aspects, industry, geographic proximity, language similarity with other countries affect the internationalization of the firm. However, Villee \& Curran (1999) that new trends and technologies continue to affect how business is conducted, which markets it serves, and how it provides those services. In has been noticed that advancements information technology and improvements in communication infrastructure have resulted in opportunities for SMEs to participate in global markets in both developing and developed countries (Todd \& Javalgi, 2007). Nowadays the use of ICT in enterprises is very important, especially in SMEs that are the majority of companies operating the world (Consoli, 2012). Thus, the adoption and use of ICT can bring benefits in terms of efficiency, effectiveness, innovation, growth and competitive advantages. Muritala, Awolaja \& Bako (2012) government should support SMEs with modern technology in order to able them to access to the necessary information relating to business opportunities which would enable them to reduce their operating cost and be more efficient to meet the market competitions. Global financial crisis, internal factors, local infrastructure and government support have been identified as critical for the internationalization of SMEs (He, 2011). Sun \& Wang (2005) recognise that rural enterprises still face many other technological challenges, such as limited or no access to broadband internet and a lack of capabilities/skills and services to use new information and communication technologies (ICTs). They state that the internet is often used for information search and communication instead of electronic transactions, due to the lack of broadband connections and issues related to trust. SMEs find it difficult to adapt to technological change, especially since such developments are happening faster and are increasingly changing the way in which SMEs do business and approach marketing. It is still not clear whether technological change will pose threats or provide 
opportunities for SMEs, but it will undoubtedly influence the way in which SMEs market their products or services.

\subsection{Problem statement}

Literature review indicates that in the Republic of South Africa, about $91 \%$ of the formal business entities are SMEs which contribute between 52 to $57 \%$ to GDP and provide about $61 \%$ to employment, however, notwithstanding the recognition of the important roles SMEs play in these countries, their development is largely constrained by a number of factors such as lack of access to appropriate technology, limited access to international markets, the existence of law, regulations and rules that impede the development of the sector (Abor \& Quartey, 2010). However, the removal of international trade barriers has brought quickly changing global markets. Large international corporations can now compete for the SMEs' market, but SMEs traditionally have not had the infrastructure or necessary resources to fight back (Don Richardson, 1999).

\section{Aim and Objectives}

\subsection{Aims}

The main aim of this study was to establish and develop an understanding of the new emerging technologies use and their significance impact in promoting internationalization of rural SMEs in South Africa with specific reference in KwaZulu-Natal (KZN) Province.

\subsection{Objectives}

- To identify various types of new technologies available and used for promoting internationalization of rural SMEs by owners/managers in KZN;

- To examine the extent of usage and the significance of new emerging technologies in promoting internationalization of rural SMEs in KZN; and

- To establish factors influencing new emerging technologies in promoting internationalization of rural SMEs in KZN.

\section{Literature Review}

\subsection{Importance of technology in the access to the International markets}

Technology drives the development of many new products and markets; it is also a major reason why some products decline (Boyd, Walker \& Larreche, 1995). Technology can also substantially influence an industry's performance. In addition to creating new products, technological developments affect all marketing activities, including communications (making available new media or new selling tools), distribution (opening new channels or modifying the operations and performance of existing ones), packaging (using new materials), and marketing research (using new data collection and analysis methods) (Lekhanya \& Mason, 2013). Achtenhagen (2011) indicates that shortage of working capital to finance exports, identifying foreign business opportunities, limited information to locate/analyse markets and inability to conduct potential overseas customers as major barriers to the internationalization of SMEs. Chiware \& Dick (2008) have shown that there is a very low level of technology use among SMEs. According to Yeh, Jung-Ting \& Chang (2007), the costs and effort involved with the subsequent implementation of technology are key factors that influence the success of small businesses

\subsection{Used technology in rural SMEs in KZN}

According to Achtenhagen (2011), many companies do not dare to internationalize due to a perceived lack of competence. Sun \& Wang (2005) recognise that rural enterprises still face many other challenges such as lack of access to broadband internet and lack of capabilities/skills and services to use the new technologies. They maintain that the internet is often used for information search and communication instead of electronic transactions due to the lack of broadband connections and the issues related to trust. The major impediments toward the non-adoption of e-marketing technology incompatibility with target markets, lack of knowledge, stakeholder unreadiness, technology disorientation and 
technology perception (Dlodlo \& Dhurup, 2010). Villee \& Curran (1999) point out that new trends and technologies continue to affect how business is conducted, which markets are served, and how services are provided. The principal conclusion is that rural businesses adopt and use ICTs because of pressures imposed upon them by their customers and suppliers (Mitchell \& Clark, 1999).

\subsection{Technology availability for SMEs in rural place}

There has been limited systematic or comprehensive research on the use and impact of ICTs on rural small and medium size firms (SMEs), yet the use and take-up of ICTs has been highlighted as an important strategic factor in the development of both rural firms and rural communities by a number of studies. Indeed, several empirical studies have found that rates of ICT adoption in SMEs lag behind those in larger businesses (Deakins, Mochrie \& Galloway, 2004).

\subsection{Benefit of Internet connectivity in rural places}

There has been a rapid increase in the use of the internet in developing countries, although this expansion is still largely an urban phenomenon. Rural communities represent both developing and developed countries with regard to access to internet services and the telecommunication connections that help transmit those services (Richardson, 1999). However, Dlodlo \& Dhurup (2010) indicate that high cost of installing infrastructure, high price of technology, large investment requirements and liquidity constraints, uncertain return on investment (ROI), limited worker expertise caused by a general shortage of highly skilled workers and insufficient training, lack of management vision, support and enthusiasm in the adoption of internet technology, inability to outsource IT expertise and bad experience in the past are barriers for South African SMEs to adopt the use of modern internet technology. Lee, Donna \& Sunghun (2012) suggest that the accumulation of technology resources may be more important when firms seek international expansion. Christina, Papastathopoulos \& Tsagris (2011) indicate that the SMEs with a greater ability not only to integrate the internet technologies into Enterprise Resource Management (ERP) and Customer Relationship Management (CRM) but also to formulate an explicit strategy for the adoption and use of ICT have the potential to extend their activities on an international level.

\subsection{Broadband availability in rural South Africa}

Broadband is the term used to describe a wide range of technologies that allow high speed, always-on access to the internet. This is most often delivered via a connection through an ADSL (Asymmetric Digital Subscriber Line) connection or cable modem service, but can also be delivered using wireless terrestrial radio antenna or satellite connections. The latter two methods of delivery are more expensive to use and are particularly relevant for rural areas where other types of provision may not be technically feasible or economically viable (Roberts \& Spurge, 2014). According to Ndenze (2012), South Africa has been left flat-footed by the rest of the world in terms of internet usage and connectivity after having been on par with the likes of North America, Europe and Australia. As a result, the Western Cape Provincial government and the City of Cape Town have now set themselves targets to have citizens in every town and village in the province get access to affordable broadband infrastructure at a minimum network speed of $1000 \mathrm{Mbps}$ (megabits per second) by 2030.

\section{Research Methodology}

The literature was used as the source of information to formulate the questionnaire for this survey. A total of 374 respondents were selected from the five rural areas in KwaZulu-Natal Province on the bases of their owners/managers roles in the business. Closed-end questionnaire was used. Personally administered questionnaires were designed and distributed to 374 SMEs owners/managers in the selected rural areas of KZN. The questionnaire was easy to read and follow. Quota sampling was used in order to obtain the desired sample. Research design was exploratory and crosssectional in nature. The primary data were collected by using the quantitative method. In order to standardize the conditions under which the questionnaires were completed; teachers from local schools in the selected areas were recruited and trained as fieldworkers. Interviews with respondents were conducted at the same period on weekdays and over weekends; the respondents' ability to answer the questionnaire was increase by the provision of a number of instructions throughout the questionnaire. 
Table 1: Profile of usable sample as per quota characteristics

\begin{tabular}{|c|c|c|}
\hline \multicolumn{3}{|c|}{ Geographic Area } \\
\hline Area & Frequency & Percentage \\
\hline Empangeni & 76 & $20.3 \%$ \\
\hline Ulundi & 96 & $25.7 \%$ \\
\hline Nquthu & 68 & $18.2 \%$ \\
\hline Escourt & 74 & $19.8 \%$ \\
\hline Kwa -Nongoma & 60 & $16 \%$ \\
\hline Total & 374 & $100 \%$ \\
\hline \multicolumn{3}{|c|}{ Period of existents } \\
\hline Age & Frequency & Percentage \\
\hline Very young (less than 1 year & 36 & $9.6 \%$ \\
\hline Young (1-5 years) & 197 & $52.7 \%$ \\
\hline Established ( $6-10$ years) & 71 & $19 \%$ \\
\hline Mature (Over 10 years) & 70 & $18.7 \%$ \\
\hline Total & 374 & $100 \%$ \\
\hline \multicolumn{3}{|c|}{ Business Size } \\
\hline Turnover Per Annum( Turnover per year) & Frequency & Percentage \\
\hline R0 - 5000 & 24 & $6.4 \%$ \\
\hline R5001 - 10000 & 67 & $17.9 \%$ \\
\hline R10001 - 15000 & 51 & $13.6 \%$ \\
\hline Over R2500 & 209 & $55.9 \%$ \\
\hline Don't know & 23 & $6.0 \%$ \\
\hline Total & 374 & $100 \%$ \\
\hline
\end{tabular}

Table 1shows the sample size of this study as obtained from the various rural areas of KZN, number of years of business existence and also respondents were asked to indicate their turnover per year.in this regard turnover is their sales revenue per year.

Questionnaire was used as measuring instrument for this survey. The main questions are summarized in table 2.

Table 2: Summary of key questions

\begin{tabular}{|c|c|}
\hline Research Area & Question \\
\hline $\begin{array}{l}\text { Do respondent have used new emerging } \\
\text { technology as source of information to access } \\
\text { international markets }\end{array}$ & $\begin{array}{l}\text { Emerging technology is used as source of information to access } \\
\text { international markets } \\
\text { Response alternatives: Strongly agree; Agree; Neutral; Disagree; } \\
\text { Strongly agree }\end{array}$ \\
\hline $\begin{array}{l}\text { Do respondents perceive modern technology as } \\
\text { important promotional tool to access international } \\
\text { market? }\end{array}$ & $\begin{array}{l}\text { Do you regard modern technology as an important promotional tool } \\
\text { to get into the international market? } \\
\text { Response alternatives: Very Important; Important; Somehow Important; } \\
\text { Somehow Less Important; not important }\end{array}$ \\
\hline $\begin{array}{l}\text { Do respondents perceive emerging technology } \\
\text { important in their areas and used to access } \\
\text { international market }\end{array}$ & $\begin{array}{l}\text { Do you perceive emerging technologies important for your business } \\
\text { Response Alternatives: Very Important; Important; Somehow Important; } \\
\text { Somehow Less Important; } \\
\text { Internet connectivity used to get access in the international market } \\
\text { Response Alternative: Strongly agree; Agree; Neutral; Disagree; } \\
\text { Strongly agree }\end{array}$ \\
\hline $\begin{array}{l}\text { Do respondents have Broadband access their } \\
\text { areas and use it to access international markets }\end{array}$ & $\begin{array}{l}\text { Do broadband available in your area } \\
\text { Broadband used to get into the international markets } \\
\text { Response Alternative: Strongly agree; Agree; Neutral; Disagree; } \\
\text { Strongly agree }\end{array}$ \\
\hline Respondents most use new emerging technology & $\begin{array}{l}\text { Which are the most used new emerging technology in your business } \\
\text { Response Alternatives: }\end{array}$ \\
\hline
\end{tabular}




\subsection{Data analysis}

The data was coded and edited to reduce errors, thus making it easier to capture the data into the SPSS computer package. The questionnaires were counted and re-counted to ensure that all respondents had answered and completed the questions satisfactorily. The data capture was double-checked in order to ensure there were no capturing errors.

\subsection{Frequencies}

Frequencies were used to determine the number of responses that each question received, and were also used to crosscheck the coding of the data. The information gathered from the frequencies thus allowed for a comparison between faculties, ages, gender, and year of study.

\subsection{T-test}

A T-test was conducted, to measure the extent to which the observed and expected frequencies differ. In this study, it was used to identify variables that were strongly associated with the dependent variables.

\subsection{Validity and reliability}

The questionnaire was assessed by the researcher and statistical experts and by pre-testing it with a small sample similar to the population, to determine content and construct for this study. No significant changes were required. Cronbach's coefficient alpha was tested, to determine a coefficient of 0.75 , and the results indicate that the reliability of the study was acceptable.

\section{Research Findings}

The previous section provided a review of literature on internationalization problems experienced by SMEs. This section reports on the key findings from the research conducted. Completed questionnaires were received from 374 respondents $(n=374)$ who either own or manage a SMEs in rural KwaZulu - Natal.

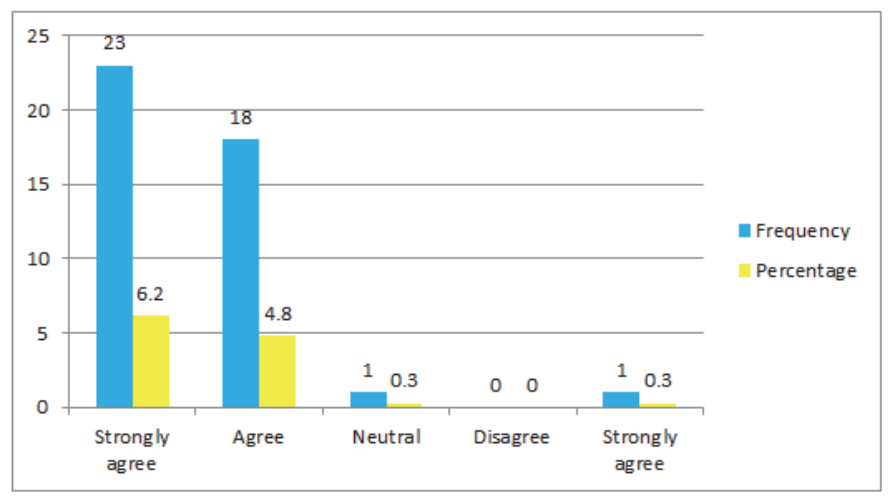

Figure 1: Source of information and technology

Figure 1 shows that on the question of the use of technology as a source of information to access international markets for their businesses in the form of a five-item Likert scale. Owners/managers were asked to indicate whether they strongly agree (1), agree (2), are neutral (3), disagree (4) and strongly disagree (5) with the statement. The large number of the respondents across rural SMEs industries regards technology as a good source of information and could help them to access international even although in many rural areas it is difficult to get access to technology facilities. These findings indicated that rural SMEs were affected by lack of technology standards/networks in rural KZN, with 23 (6.2 percent) strongly agreeing and 18 (4.8 percent) agreeing with the statement. There are also 1 (0.3 percent) of the respondents 
who are not sure whether they are agree or not. While only 0.3 of the respondents disagree. A T-test goodness of fit test showed this finding to be statistically significant ( $T$. test=13.349; $d f=42 ;$ mean=1.55814; $P=.000$ ).

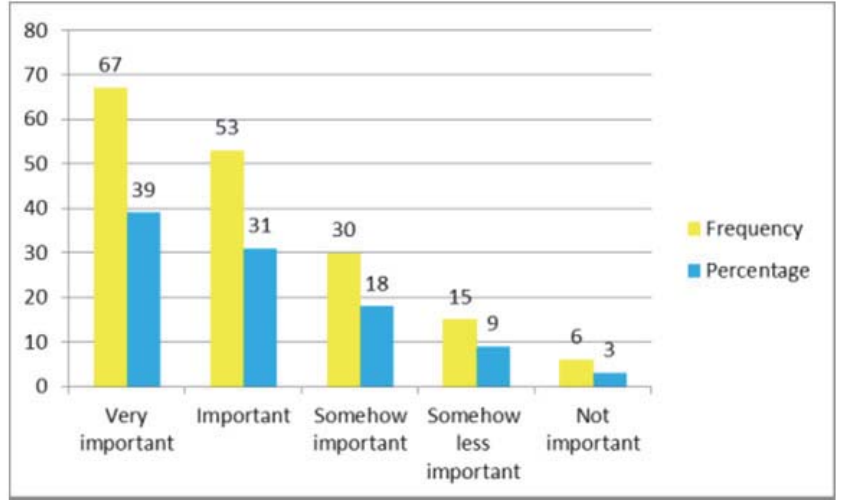

Table 2: Modern technology as a promotional tool for connecting Rural SMEs with International market

Table 2 illustrate that most of the respondents, 67 (39 percent), consider modern technology such as internet as very important promotional tool that can be used for rural SMMEs access the international markets. 53 (31 percent) of the respondents believe that it is important promotional tool. However, 30 (18 percent) of the respondents were not clear where if whether they agree with the stamen or not. While very few number of respondents 15 (9 percent) and $6(3$ percent) of respondents indicated that it is somehow less important or not important. A T-test goodness of fit test showed this finding to be statistically significant ( $T$-test=24.271; $d f=170$; mean $=2.06433 ; P=.000$ ).

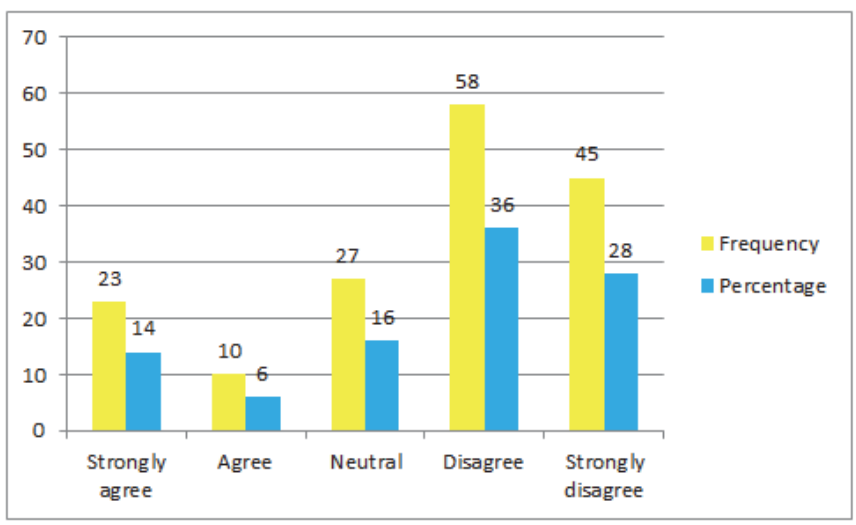

Table 3: Accessibility and availability of communication technology

Table 3 reveals that the majority of respondents 58 (36 percent) and 45 (28 percent) disagree that there is enough accessibility of and availability of communication technology such as ICT in most rural areas of KZN. While 27 (16 percent) were neutral with the statement. However, less than half of respondents who participated to the question 23(14 percent) and 10 (6 percent) agree with the statement that communication technology is accessible and available in their areas. $A$ T-test goodness of fit test showed this finding to be statistically significant $(T$-test $=34.126$; $d f=162$; mean = $3.56442 ; P=.000)$. 


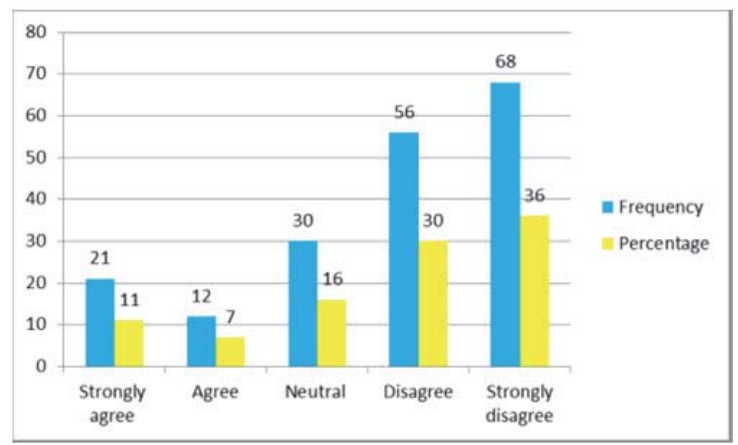

Table 4: Internet connectivity in rural South Africa

As show in table 4, 56 (30 percent) and 68 (36 percent) of the respondents disagree that internet connectivity is available and it used to access international markets. However, 30 (16 percent) of the respondents were neutral with regard to the statement. While small number of the respondents 21 (11 percent) and 12 (7 percent) agree with the statement. A T-test goodness of fit test showed this finding to be statistically significant (T-test=38.840; df=186; mean=3.73797; P=.000).

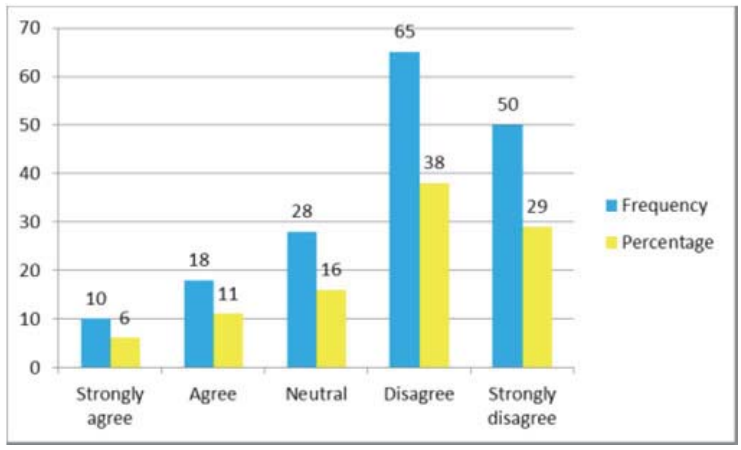

Table 5: Broadband availability in rural KZN

The results shown in table 5 reveal that 65 (38 percent) of the respondents strongly agree and 50 (29 percent) agree that broadband is available and help rural SMEs owners/managers to access international markets. A total of 28 (16 percent) were neutral, 10 (6 percent) and 18 (11percent) disagree. A T-test goodness of fit test showed this finding to be statistically significant ( $T$-test $=23.392 ; d f=170 ;$ mean $=2.16959 ; P=.000)$.

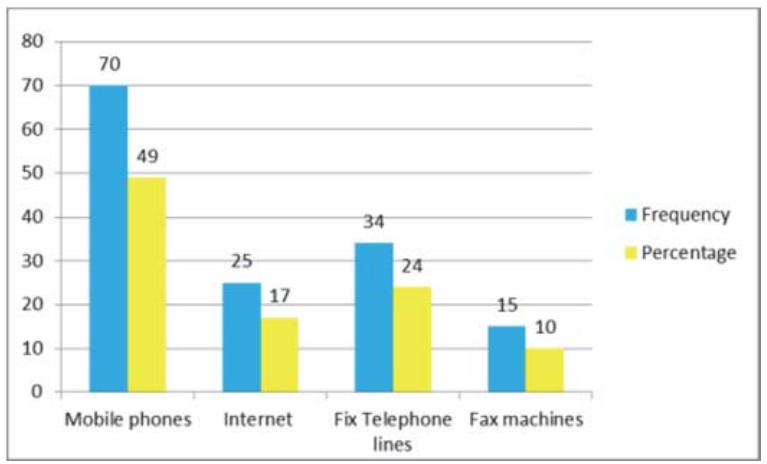

Table 6: Most used technology in rural SMEs in KZN 
Of the 374 respondents in Table 6, 70 ( 49 percent) indicated that they use mobile phones in their areas but not much on business related matters rather on family and friends communication. 25 (17 percent) of respondents use internet for both business and friendly communications. While 34 (24 percent) of respondents use fix telephone land lines for family and friends communication. Very few number of respondents 15 (10 percent) use fax machine for business communication purposes. A T-test goodness of fit test showed this finding to be statistically significant ( $T$-test=21.961; $d f=143$; mean=1.95833; $P=.000)$.

\subsection{Limitations}

This study used a structured questionnaire which limited the respondents to say more about their feelings with regard to the constraints that affect development in their areas. However, the findings are limited by the study's exploratory, quantitative nature and the small sample that did not include other rural areas in other provinces in South Africa. Therefore, generalizing should be done with care and therefore, further research should be conducted with larger samples that will include others province.

\section{Conclusions and Recommendations}

\subsection{Conclusions}

Since the use of new emerging technology is rapidly growing in South Africa in both the business and social sectors, SMEs owners/ managers in rural KZN should be made aware of the benefit and the importance using emerging technology to get access into the international markets. They should be made aware of the value of using new emerging technologies such as social media and social networking in promoting their business. The cost benefit of using and advantages of using new emerging technology as international marketing tools for rural SMEs products and services must be clearly understood.

\subsection{Recommendations}

In order to enable the internationalization of Rural SMEs of South Africa emerging technologies in their respective areas must be available and be fully utilised. It is recommended that more needs to be done training and capacity skills on the use of ICT and other related technologies in rural South Africa communities. Apart from challenges of broadband availabilities and electricity in some areas, rural SMEs also face with many barriers such as poor telecommunications infrastructure, lack of marketing knowledge and skills and business management incompetence. South African rural national development strategic plan should include strengthen the human resource base by ensuring strategic ICT coordination in its policy development programme delivery in the rural areas. Technology and business agencies should be established in rural areas with specific reference to KZN.

\section{References}

Abor, J. \& Quartey, P. (2010). Issues in SME development in Ghana and South Africa, international research journal of finance and economics, 39: 1450-2887.

Achtenhagen, L. (2011). Internationalization competence of SMEs. Retrieved from: http://eng.entreprenorskapsforum.se/wpcontent/uploads/2012/01/internationelization comp_webb.pdf (Accessed 17/06/2014).

Boyd, H.W.JR., Walker, O.C. Jr. \& Larreche, J. 1995. Marketing management: A strategic approach with a global orientation, 2nd Ed. Chicago: Irwin.

Chiware, E. R. \& Dick, A. (2008). The use of ICTs in Namibia's SME sector to access business information services. The electronic library, 28(2): 145-157.

Christina, C. B., Papastathopoulos, A. \& Tsagris, M. (2011) The influence of web-based enterprise systems on SMEs' Internationalization process. International bulletin of business administration, (12).

Consoli, D. (2012). Literature analysis on determinant factors and the impact of ict in SMEs. Procedia - social and behavioral sciences, 62: 93-97.

Deakins, D., Mochrie, R \& Galloway, L. (2004). Rural business use of information andcommunications technologies (ICTs): a study of the relative impact of collective activity in rural Scotland. Strategic change, 13 (3): 139-150.

Dlodlo, N. \& Dhurup, M. 2010. Barriers to e-marketing adoption among small and medium enterprises (SMES) in the Vaal triangle. Acta commercii, 167.

He, S. (2011). The influential factors on internationalization of the SMEs in China: on wenzhou's shoe industry and policy implications. 
Research in world economy, 2(1).

Lekhanya, L. M. \& Mason, R. B. (2013). The use of marketing strategies by small, medium and micro enterprises in rural KwaZulu-Natal. South African journal of entrepreneurship and small business management, 6: 39 -56.

Lee, H, Donna, K. J. L \& Sunghun, L (2012). SME Survival: The impact of internationalization, technology resources, and alliances. Journal of small business management, 50 (1): 1-19, 2012.

Mitchell, S. \& Clark, D. (1999). Business adoption of information and communications technologies in the two-tier rural economy: some evidence from the South Midlands. Journal of Rural Studies, 15: 447-455.

Muritala, T, Awolaja, A. \& Bako, Y. (2012). Impact of small and medium enterprises on economic growth and development. American journal of business and management, 1: 18-22.

Ndenze, B. (2012). Affordable broadband on cards for rural SA. Retrieved from: http://www.iol.co.za/news/south-africa/westerncape/affordable-broadband-on-cards for-rural-sa-1.1215153\#.U5mvi_mSxic (Accessed 12/06/2014).

Oseh, C. K. (2013). Factors associated with internationalization of small and medium enterprises in Thika town, Kenya. European journal of management sciences and conomics, 1(3): 128-136.

Richardson, D. (1999). The Internet and rural development. Retrieved from: http://www.fao.org/sd/Cddirect/CDre0041.htm (Accessed 12/06/2014).

Roberts, C. \& Spurge, V. (2014). A comparative study of broadband technology in rural areas: The availability and use by small office occupiers and the effectiveness of use for e -commerce. Retrieved from: http://www.prres.net/papers/Spurge_Broadband Technology_An_Appraisal_Of_Th_Availability.Pdf (Accessed 13/06/2014)

Sun, Y. \& Wang, H. (2005). Does Internet access matter for rural industry? A case study of Jiangsu, China. Journal of Rural Studies, 21 (2): $247-258$.

Tahirou, Y. A., Jouali, J. \& Arwata, S. B. (2013). Identifying factors influencing Moroccan SMEs internationalization. International journal of economics and management $1(3)$.

Todd, P. R. \& Javalgi, R. G. (2007). Internationalization of SMEs in India Fostering entrepreneurship by leveraging information technology. International journal of emerging markets, 2 (2): 166-180.

Villee, P. A. G. \& Curran, M. G. (1999). The 21st century: Meeting the challenges to business education, New Jersey: National business education association.

Wilson, K. (2013). Encouraging the internationalization of SMEs: Chapter 2. http://www.gvpartners.com/web/pdf/Chapter_2_ Wilson_FINAL.pdf (Accessed 09/06/2014).

Yeh, Q. \& Jung-Ting Chang, A. (2007). Proliferation of computers among Taiwanese SMEs.International journal of entrepreneurship and innovation management, $7(1)$ : 51-73. 